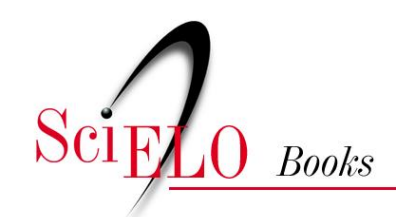

\title{
Seduepb
}

\section{Um reino do outro mundo, como itinerário da memória}

\author{
Geralda Medeiros Nóbrega
}

\section{SciELO Books / SciELO Livros / SciELO Libros}

NÓBREGA, GM. Um reino do outro mundo, como itinerário da memória. In: Hermilo Borba Filho: Memória de resistência e resistência da história [online]. Campina Grande: EDUEPB, 2015, pp. 165-

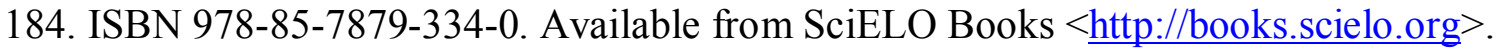

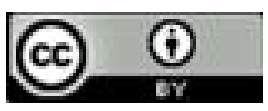

All the contents of this work, except where otherwise noted, is licensed under a Creative Commons Attribution $\underline{4.0 \text { International license. }}$

Todo o conteúdo deste trabalho, exceto quando houver ressalva, é publicado sob a licença Creative Commons Atribição 4.0.

Todo el contenido de esta obra, excepto donde se indique lo contrario, está bajo licencia de la licencia $\underline{\text { Creative }}$ Commons Reconocimento 4.0. 


\section{UM REINO DO OUTRO MUNDO, COMO ITINERÁRIO DA MEMÓRIA}

Quando se disse que o reino não era do nosso mundo foi para estabelecer com o que devia existir. É sugestão para lutar, Atacar e transformar o que de errado houver.

(Hermilo Borba Filho)

Numa leitura do texto hermiliano, em que se depara com o mundo objetivo, é natural deparar-se com o mito, que mantém um significado e acrescenta outros, decodificados nos bastidores do discurso, enquanto subsidia a memória, captada sob diversos aspectos: lembrança ou reminiscência, memória social ou coletiva, memória institucional, memória literária, memória mitológica, memória histórica e memória registrada. Apresento, através dos temas suscitados, também uma reflexão sobre a relação entre memória e a repressão política, em tempo de ditadura, a partir de uma memória discursiva, reconhecendo que textos fundadores de memória são respaldados pelos mitos, relatos, enunciados, paráfrases, na esteira de Achard (1999). Muitos dos contos de Borba Filho são representativos de um contexto que permite relacionar uma memória como o que ainda é 
vivo na consciência do grupo para o indivíduo e/ou para a comunidade, sob a perspectiva de Halbwachs.

Para introduzir a denúncia do preconceito racial [e aqui se chama a atenção para dizer que "identidade racial brasileira e as formas brasileiras de racismo estão no centro do debate político cultural" (SOVIK, 2003, p. 21)], o narrador, em "O almirante" (GEP, p.1-13), disfarça, através de gestos da personagem, o constrangimento da situação: "Jamais pensara que o Almirante Pederneira Sobral fosse negro. Dominou-se a custo, embora mais vermelho adiantou-se de mão estendida, forçando um sorriso". É a visão de mundo conservadora que prevalece, caindo por terra o mito da igualdade entre os Homens. Por trás da "igualdade", está presente um tempo anterior do escravagismo e aristocracismo da sociedade grega (LEMINSKI, 1994), que ainda atua, embora sob outros moldes. $O$ autor consegue miticizar a linguagem que passa a funcionar, sob os auspícios de Cassirer (1985, p.115) como "uma forma particular de configuração".

Já no conto "Vestidos e Sapatos" (AMS, p.97-100), o preconceito racial é estabelecido pelo próprio discurso do narrador que, descrevendo a personagem, diz: "nariz tipo grego ou coisa assim, lábios finos quase sem zingomas, uma preta branca, até parece uma branca pintada de preto" (p.9). Nesta linguagem visual, destaca-se uma palavra chave, "grego", alusiva à Grécia e, por extensão, aos tempos primordiais, mitológicos. A personagem muda o nome Esperidiana para Diana, nome alusivo à casta deusa mitológica da caça e se transforma em prostituta e passa a ser caçadora de homens. Há, pois, uma desconstrução do mito, pois a deusa Diana era casta. A persona tem uma fixação no número trezentos e se prostitui para comprar todos os anos trezentos vestidos e trezentos sapatos. Trezentos sendo um múltiplo do número três, induz a pensar em expansão, crescimento, implementação. 0 número três é um número sagrado, é o signo do retorno e da purificação. Antes de Diana atingir os trinta anos, comprou trezentas rosas vermelhas e sentou-se com toda a calma na grande mesa de jantar, tomou trezentos cálices de genebra, "fechou os olhos, estendeu-se 
na cama e ascendeu. As mulheres de Quiterinha herdaram trezentos vestidos e outros tantos pares de sapatos quanto foram os anos que Diana amou para juntá-los" (AMS, p.100).

Não passa despercebido o plano simbólico encaixado na linguagem mítica, o que talvez não explique o mito, mas o subsidia no plano semiológico, o que permite recorrer a Barthes (1980, p.77) para dizer que "a linguagem do oprimido tem como objetivo a transformação", linguagem que se manifesta como fala, gesto, atitude.

Borba Filho, na verdade, transforma o mito, desarticulando-o e reativando-o numa nova ordem, quando fabuliza o tema. Eros, cedendo lugar a Tânatos, configura o tema da morte como mudança de estado, ascensão a um novo plano de vida. O real, presente através dos elementos materiais, transmuta-se em símbolos, situação em que eleva o mito "à esfera da permanência, ou seja, contínua presença" (GRASSI, s.d., p. 76). Recorrendo o narrador a uma polivalência simbólica induz que "a função dos mitos e dos símbolos na literatura é a de veiculadores internos que emergem da consciência coletiva, transcendendo nossa compreensão espaço-temporal" (PAZ, 1995, p.48). O final do conto, cuja persona é Diana, mostra o gesto de "estender-se na cama" como rito da espera e "ascender" é movimentar-se em busca de algo, quem sabe, o infinito. O mundo natural, representante de um tempo/ espaço específico, abre-se para dar respostas, se é que o mito permite esta interferência. Afinal, na lição de Barthes (1989, p.178) aprende-se que "é isso que devemos procurar: uma reconciliação entre o real e os homens, a descrição e a explicação, o objeto e o saber".

Mas se o mito não explica, sugere, associando-se ao silêncio que paira sobre o discurso literário hermiliano. Por isto, muitas vezes, diante do texto, questiona-se não o que está explícito, mas o que fica subentendido. A expressão da experiência religiosa, advinda de culturas primitivas e de seus ritos, encontra-se com o mito, quando se dá o resgate de um passado, longínquo, ao mesmo tempo que "fabula e organiza os mitos tais como vividos e acreditados por sua comunidade" (LEMINSKI, 1994, p.75). 
Os animais instigam a imaginação popular, também na literatura de Borba Filho, não só num sentido factual, mas também como imagens fantásticas que surgem no lugar do ato desencadeado. Neste contexto, podemos nos deter no mito, na visão de Ribeiro (1986, p.45): “O mito sempre se refere a acontecimentos que tiveram lugar no tempo, um passado muito distante, o tempo dos primórdios. Mas o que dá valor operatório ao mito é que o modelo específico descrito é perene". o mito responde a várias solicitações, assumindo importância decisiva no plano do real, conforme posição de Caillois (s.d.).

No conto "A cocheira" (AMS, p.47-49), o narrador retorna ao passado e focaliza um menino que, quando se sentia em liberdade, aprisionava os pássaros em gaiolas. Até que, numa tarde, entra numa velha cocheira e se depara com animais, tais como, um burrinho engatado com um cavalo que tinha um aspecto diferente, um peru de crista serrilhada e um tatu, que o acompanhava na volta para casa, tornando-se invisível para os outros. Pela manhã, voltando à cocheira, só encontrava teias de aranha, cheiro de mofo, cocho vazio, nada de bichos. E assim, durante um ano, repetiam-se os mesmos fatos: "de manhãzinha tudo velho de tardezinha tudo novo e o passeio do tatu". Até que numa tarde de festa, o tatu tornou-se visível e "mataram o tatu e o comeram". A partir da morte do tatu só restou o silêncio na cocheira e os trastes velhos. "Só muito tempo depois, quando o menino já era contador de estórias entre a idade de homem e a idade de velho", houve um reencontro, a campo aberto. "Os bichos levantaram a cabeça e olharam para ele. Depois, empinando, esquiparam e sumiram-se na noite" (AMS, p.49). Termina, então, o texto e instalase o mito, "fantasia que exige que se acredite nela, estando ligada a um ritual" (SIMONSEN, 1987, p.88). Infiro que, apesar da viagem no tempo, com ou sem deslocamento de espaço, há sempre, no homem adulto/velho, uma tentativa de reter a infância; o mito seria, pois, o retorno à infância de que a adultidade não consegue afastar-se, sendo possível localizar semioses que se contrapõem, respaldando a visão mítica da infância: 
a) Infância $\mathrm{x}$ adultidade: $\mathrm{o}$ menino já era contador de estórias $\mathrm{x} a$ idade de homem e a idade de velho;

b) Liberdade $\mathrm{x}$ encarceramento: corria para a margem do rio $\mathrm{x} o$ terraço entupido de gaiolas;

c) Atividade $\mathrm{x}$ imobilidade: descendo a ribanceira e trepando na gameleira $x$ gaiolas no seu quarto;

d) Real x fantasia: quando voltava num fim-de-tarde com um sanhaço já livre do visgo e o Peru-de-Papo-pra-Cima que nem não chegava mesmo a ser peru;

e) Espaço aberto $\mathrm{x}$ espaço restrito: campina enluarada $\mathrm{x}$ gaiola;

f) Semelhança $x$ diferença: um bicho que tinha cara de peru $x$ no corpo restante era o de um avestruz sem rabo;

g) Desaparecimento x retorno: e o mais eram teias de aranha, cheiro de mofo, cocho vazio, nada de bichos $\mathrm{x}$ os bichos levantaram a cabeça e olharam para ele.

Borba Filho remete, pois, para a sociedade uma criação primitiva de seus próprios mitos formais (BARTHES, 1984). A temática do conto, nitidamente simbólica, reforça a escritura hermiliana que instala uma visão mítica que engloba a cultura, a memória, a tradição, a vida, enfim. Memória, neste contexto, se baseia, na ótica de Pêcheux (1999, p.56) "nos sentidos entrecruzados da memória mítica, da memória social inscrita em práticas [...]" e, ainda, tudo o que toca as disciplinas de interpretação: logo a ordem da língua e da discursividade, a da "linguagem", a da "significância" (BARTHES) do simbólico e da simbolização (PÊCHEUX, 1999). Isso pode ser ilustrado pelo conto "O boi" (AMS, p.57-59). O boi está presente no bestiário nordestino e pelas regiões da pecuária vive uma literatura oral louvando o boi, suas façanhas, agilidade, força, decisão (CASCUDO, 1969). Este texto já foi apresentado, mas o utilizo agora para reforçar o bestiário. Este boi aparece de cinquenta em cinquenta anos; tem instinto assassino e sempre que aparece mata uma pessoa. Leonardo das Benevides de Souza Paiva foi acalentado no "Boi, Boi, Boi, Boi da cara preta, o 
menino vai pegá-lo, não tem medo de careta". Como vivia em função do boi, Leonardo marca o casamento para o inverno em que o boi iria aparecer. E o boi aparece. $\mathrm{O}$ mito, tornado uma realidade significativa para a personagem, determina a sequência e a parte final da narrativa. O narrador aproxima memória e tradição, representadas pelo:

a) Ênfase no popular, centrado na linguagem: "presenciou duas mortes do boi e ficou pra semente morrendo com bem cem anos na cacunda";

b) Referência: ao contador de "estórias": "o pai do avô contava que o Boi aparecera pela primeira vez lá pelos idos de setecentos”;

c) Localização e temporalização dos fatos: "chegou no engenho era de tardinha";

d) Descrição como preservação do mito: "era espácio, as patas dianteiras meio curvas, branco de cara preta";

e) Gesto como apanágio do rito: "bufou escavou terra";

f) Morte como destruição: "o chifre varou Chico Novilho que não disse nem ai, nem suspirou, nem estrebuchou, pronto estava";

g) Tempo progressivo, cíclico: "de cinquenta em cinquenta anos";

h) Busca do incognoscível: "não tinha outro fito na vida: o Boi";

i) Domínio do fortuito: "é como cometa";

j) Jogo de linguagem: “pega não pega, dá que não dá, é agora e não é, vai raiar o dia";

k) Retorno ao princípio (infância): "Boi, Boi, Boi, Boi da cara preta, o menino vai pegá-lo, não tem medo de careta";

1) Vinculação a uma esfera de atuação popular: "cadê o Boi?";

m) Identificação entre seres diferentes: "o Boi se ajoelhou, o Homem se curvou";

n) Vigor do já dito: "levanta-te Boi vamo-nos s'embora";

o) O festivo como forma de identificação: "na festa do casamento do Homem, na festa do Boi e do Homem"; 
p) Animização/antropomorfização: "e quem primeiro foi ao ataque foi o Boi não pegando o Homem, e depois foi o Homem que não pegou o Boi";

q) Dupla invencibilidade: "o Homem no Boi e o Boi no Homem";

r) Símbolo de força e tenacidade: "o Boi e o Homem";

s) O popular respaldando o mito, intertextualidade como espetáculo popular do Bumba-meu-boi: "o Boi varava, o Boi matava, cadê o Boi?, o Boi se foi, foi-se, de noite e de dia, na barra do dia, foi não foi, o Boi";

t) Imagens fortalecendo o mito: "bumbas e zabumbas".

Barthes (1971, p.19-20) arremata o que foi exposto acima: "Todas as classes, todos os grupos humanos têm suas narrativas, e frequentemente essas narrativas são apreciadas em comum por homens de cultura diferente e mesmo oposta; a narrativa ridiculariza a boa e a má literatura [...], a narrativa está aí como a vida."

\section{Morte e vida}

Em muitos dos contos hermilianos, há uma semiose latente de um processo de mudança, embora o narrador não consiga ultrapassar a imanência do discurso literário. Às vezes, o dado real tem por alicerce o fantástico, introdutor de uma aparente utopia, pela inverossimilhança dos elementos utilizados. Isso, em linhas gerais, é o teor do que focalizo agora.

No conto "O peixe" (AMS, p.107-111), a personagem "Mucurana passou meses com o peixe pendurado no pescoço e o que se via agora era o esqueleto do peixe [...], o peixe reencarnou à vista de todos no primeiro dia da semana santa, na beira do Una, lançando-se nas águas" (p.110-111). o peixe, como símbolo de Cristo, induz, numa visão popular, que a possibilidade de uma mudança está em Deus, o que resulta no plano espiritual como vida plena. Significa dizer que a alienação 
imposta fecha todos os caminhos da libertação. 0 escritor faz uso do fantástico para expor o ponto de vista que representa a visão crítica de seu projeto literário. Este meu comentário remete para aquilo que Mendilow (1972) defende como transitoriedade de toda as formas da vida moderna, delegando-a à arte, e neste contexto, à literatura da qual foi retirado aquele sentimento de estaticidade social que marca a desintegração ameaçadora de todas as formas de vida. É o mito da transitoriedade que desgasta, gradativamente, a segurança, no plano vital da trajetória do homem no mundo.

Então, "a função estética deve ser apreendida como uma função social específica: modo específico de conhecimento e de transformação do real" (VERNIER, 1977, p.102), mas quando se encontra com o mito subverte esta finalidade, pois o mito pode apresentar-se como fuga do real. Exemplo típico é o conto "Ato de natal" (AMS, p.72). Um tema popular que explora elementos circenses, destaca Bitom, o Palhaço. 0 circo anuncia a Pantomima do Nascimento na véspera do Natal, e espalha alegria: "tomem cantos e danças e passas e doces até na casa dos pobres, perus de papos recheados em casas dos magníficos". 0 espetáculo popular promove a confraternização, pois através dos espetáculos populares, as pessoas descobrem um sentido para alegrar-se, ao mesmo tempo que se pode destacar a sintonia do narrador com a cultura popular, em que o texto se torna plural: igual e novo e não o verdadeiro texto, pelas semioses que conotam a realidade (BARTHES, 1980).

Bitom, o Palhaço, garante a sobrevivência do mito, pois através do processo metamórfico imita os deuses mitológicos que tinham o poder de transformarem-se, assumindo formas variadas, aplicadas a objetivos estabelecidos. 0 modelo mítico, prestando-se a várias modalidades, dá significação e sentido à existência. No discurso hermiliano, o mito não ressalta apenas o dado mitológico dos tempos primordiais, mas patenteia uma realidade de fuga do mundo real, situação em que o retorno ao princípio representa uma reatualização do mito, ligada à renovação da comunidade inteira, restabelecendo "o acesso a um novo 
modo de existência" (ELIADE, 1972, p.12, et pas.). Trata-se sempre de abolir o tempo decorrido, de voltar atrás e de recomeçar a existência com todas as suas virtualidades intactas. 0 regressus ad uterum para um novo nascimento remete à comprovação mítica de que a criança "vive um tempo mítico, paradisíaco". o conto é constituído de vinte e uma linhas e isto não neutraliza o teor significativo e exemplar. A interpretação atinge o vazio do texto, o não-dito, o que pode ainda ser dito, através da interpelação do real e do arranjo textual, conjugados ao mito, que centraliza número, sequência do tempo e uma linguagem que reflete, no campo da fantasia, a síntese do mundo real, nada havendo a acrescentar, mas tudo a refazer, fazendo da literatura algo sério:

Bitom o Palhaço, na casa dos sessenta, chegou postou-se diante do espelho quebrado, começou a pintar a cara, às sete terminou com cinquenta: às oito, tomando uma cachaça, estava com quarenta - era aquilo todos os anos, na noite do vinte e quatro para a aurora do vinte e cinco - entrou no picadeiro, às nove com trinta: às onze, de novo diante do espelho, era Bitom o Palhacinho, com dez; tirou a tinta foi caminhando para a infância, os artistas abriram alas, ele foi andando e ficando mais menino, atravessou o picadeiro e desapareceu atrás das cortinas, a Trapezista nova perguntando ao Mestre-de-Cerimônias: Para onde ele vai? Ao que o Mestre-de-Cerimônias fazendo uma cara de espanto, respondeu-lhe meio áspero, meio gozador: Oi, não sabe?, Ele vai nascer (AMS, p.72).

O texto hermiliano dá acesso a um universo mágico que não cessa de destacar os mesmos aspectos. No entanto, a monotonia aparente destas repetições parece acenar para uma realidade: a vida humana é assim mesmo. E o narrador hermiliano consegue dar veracidade aos fatos através de fórmulas fixas, clichês, repetições. Atua ainda 
como um profeta, que imbuído da defesa da sociedade, confessa a realidade existente, o que é captado nas entrelinhas. Nas pegadas do mito, expõe uma cosmovisão de mundo que revela a capacidade de estilização quando, através do manuseio da linguagem, retira todos os efeitos do plano discursivo. Parece, ainda, deixar entrever que os dados históricos e sociais constituem-se como invólucro essencial de uma percepção diante dos fatos da vida. Captando tudo o que impressiona a imaginação popular, o autor dota a sua literatura de contos de todos os ingredientes que dão sentido à vida do povo. A morte apresenta-se quase sempre como um fenômeno natural, como algo apenas esperado, que não causa nenhum impacto, morte como instrumentalizadora do próprio mito. A morte, por exemplo, em "Episódio de um homem bissexto", é vista como ausência de movimento: "ele ficou inerte", embora tenha sido antecedida do ritual do ato sexual. Em "As lagartixas indianas" é a ausência de ar que determina a morte da persona, embora a este silêncio do ar se posponha barulho e rumor: "Filogônio procurando ar e não encontrando [...] sem ouvir barulho da casa caindo, mas dentro da cabeça, ainda o rumor da mastigação das dozes terroristas" (GEP, p.35), as lagartixas nativas que mastigaram as cabeças das lagartixas indianas. 0 mito, no entanto, não respalda apenas a morte, mas também a "casa", a casa confundindo-se com o próprio homem, que perdendo o seu espaço de localização, precisa transplantar-se para novos parâmetros ou se aerificar, como forma de alcançar um novo espaço que, refazendo a experiência do mundo mítico, aponta para novas experiências que podem atingir também espaços outros, como o espaço do sagrado.

Em "Dom" (GEP, p.58-73), a morte apresenta-se com um teor lendário. O verbo "envultar-se", neologismo explicado através da metalinguagem, prepara o desfecho do texto na perspectiva mítica, em que a morte não se materializa. Antecede a morte, no plano do discurso, uma apoteose da persona: "a glória da cidade, o mágico excelso, o vendedor de ilusões, o taumaturgo, o messias" (signos de diferença), "batidas de coração" (sentimento expectante), "silêncio 
pedido com as mãos" (linguagem gestual), "compreensão da mágica" (código fantasioso), "um pouco de essência" (impressão olfativa), "a bandeira" (símbolo de civismo), "notas graves do piano" (significante musical), "dança em pirueta" (significado cinético), "ressurreição" (mudança de vida), "um sinal" (sintoma do que acontecerá), "o funil" (simbolismo do real), "o fogo" (agente de transformação), "cinzas" (instrumento de morte), linguagem mitificada, pois: "[Afinal "Dom"] preso como comunista envultou-se, quer dizer, tornou-se invisível: o resto é lenda" (GEP, p.73).

A personagem de "Os tropeiros do céu" (SDC, p.27-41), Jesú que fazia o papel principal no drama "Vida, paixão e morte de Nosso Senhor Jesus Cristo, só que a subida ao céu mesmo de vera, embora em corrupio". O narrador coloca na boca dos outros participantes que dançavam "como mandava o mestre, esclareciam, já que a morte não existe". Há uma situação de desequilíbrio e a morte aconteceu no plano da história, pois Jesú não conseguiu segurar a corda mestra. A corda, símbolo do vínculo existente entre o céu e a terra, passa aqui por um processo de desconstrução. A terra se distancia e o céu, representando o transespaço, confirma o mito do céu como lugar da morada dos deuses, para o qual as almas subirão após a morte. Daí poder-se inferir que a morte não existe porque a subida aos céus inicia a vida plena, o que confere aos mortais uma meta transcendental.

A morte de Zumba-sem-Dente é antecedida do mito de retorno de uma nova vida, representando um "novo nascimento", segundo Eliade (1992): "[...] plantou bananeira no meio da cela, depois brincou de academia e de apanhar pedras imaginárias, dez num só raspão, no quarto dia passou a falar com dificuldade [...], engatinhando no quinto [...] caindo no tatibitate no útero para sempre" (p.52).

O tema da morte é tratado por Borba Filho constantemente e a perspectiva mítica se encaixa também no seu projeto estético. No texto "As esporas" (SDC, p.55-58), a morte está associada ao adultério e tortura. 0 mito desconstrói o símbolo "espora" (virtudes nobres) e o símbolo "prata" (pureza) evidenciando o símbolo mítico da fidelidade, 
que não sendo preservada, atrai o castigo. As esporas são tratadas "à maneira de sagrado". As esporas e o brilho da prata. Isto e o signo do silêncio. O narrador inicia o texto: "Era de nome Clementina, ninguém não mais se lembrava dela, já que se finara pouco tempo depois do casamento" (GEP, p.55), lembrando que o mito do esquecimento, relacionado à perda de memória social, indicia no mundo real, os parâmetros da sociedade discriminadora. O texto transmite uma visão sinestésica do mundo e as imagens se entrechocam e se atropelam, minando a narrativa de aspectos descritivos, com predomínio do sensorial-auditivo. Prefiro, no entanto, destacar as sensações tátil e visual, pois através destas imagens há um encaminhamento para o desfecho final: a morte. "Morte, consequentemente, é o retorno a um estado primordial e perfeito [...]” (ELIADE, 1972, p.111).

Destaco, para efeito de apresentação, as sensações mais marcantes do texto, procurando também mostrar como a tortura se instaura em torno da palavra "judiação": "Na penumbra os olhos frios do marido verrumando, e no ano que durou a judiação nem uma palavra, somente os olhos fitos nela" (GEP, p.55).

A personagem, impotente diante do que lhe foi imposto, aceita passivamente o castigo, evidenciando o elemento mítico da fraqueza da mulher:

\begin{abstract}
[...] desinfeliz, seca, os olhos esbugalhados, sem palavra, manejada pela atmosfera fria, escura, verde da casa. Em cima da mesa, numa bandeja de prata, nas três refeições do dia o par de esporas, por sinal também de prata e era prata sobre prata. A comida não descia, quem há-de?, o bolo na garganta, só. Isto e o silêncio. E mais os olhos fitos nela (GEP, p.55).
\end{abstract}

Como situa Bachelard (2000, p.19), “o espaço percebido pela imaginação não pode ser o espaço indiferente [...]. É um espaço vivido [...]. Concentra o ser no interior dos limites que protegem". E o narrador, 
enfocando um tema universal, registrou a transfiguração do espaço, localização do Homem, sacralizando a intimidade da família: casa, mesa, quarto, cama. "No quarto, na parede confronte os pés da cama, substituindo imagem de santo, o par de esporas, levado em cerimonial [...]" (GEP, p.55).

o narrador, retorna ao tempo, para focalizar o adultério. Vale-se do plano imagético:

O som das esporas que subiam a escada da frente naquela tarde chuvosa. [...]. Era o primeiro cheiro de homem afora o do marido que sentia debaixo das telhas. [...], olhava o marido dormir, boca meio aberta, o ar que saía tal qual silvo de cobra. Nas oiças, o pigarro do homem (GEP, p.55).

Aos poucos, projeta-se o esperado. A palavra substituída pelo gesto, indicador do ritual:

Entre os dois se estabeleceu uma conivência muda [...]. Se estabeleceram no terraço, durante algum tempo houve só poucas palavras até que se levantou e sem mais ergueu-a da cadeira de balanço, no acocho apertado, beiço com beiço. $O$ corpo da mulher tremia, tremia mas não recusava. E foi ali mesmo, em pé, contra a parede, no semi-escuro, na atrapalhação das roupas (GEP, p.56).

No retorno, os dois amantes:

[...] se portara, na presença do marido como se nada de nada e não houve coito, não era para haver [...] noutra visita, não houve, só estavam nas carícias primeiras, também no terraço ela sob o beijo abriu os olhos por um instante e viu um vulto de homem recortado contra o céu (GEP, p.57). 
Na situação quase real descrita pelo narrador, a linguagem da narrativa procura traduzir a realidade. Há como uma premonição, estabelecida pelo cruzamento dos adjetivos "oca" e "seco": "Sentiu uma frieza de morte, oca, o corpo sem governo [...], o marido já vinha subindo a escada, nem sequer olhou pra ela, num tom seco ao homem: Venha comigo" (GEP, p.57). O silêncio está nos interstícios do texto, não havendo explicação para nada. A tensão dramática fica a cargo das imagens, metáforas sinestésicas que compõem o quadro da tortura. A imagem atinge a culminância em "prata contra prata":

Bateu com a faca em qualquer coisa metálica [...] e o ruído foi um choque para ela: era o das esporas [...] seus olhos foram para a bandeja diante dela e lá estavam as esporas [...], na luz quebrada da sala [...]. O marido com a faca, continuava a bater levemente nas esporas, um tinido manso, contínuo, nervento (GEP, p.58).

Neste ponto do texto, há um retorno à parte inicial, o que promove a circularidade da história preparando o desfecho. A "imagem" substitui a "palavra". O material linguístico, trabalhado pelo narrador, encaminha o conto na direção do mito, a morte como reparação da culpa. A parte final converge para a transformação do narrador em comentarista. Percebe-se, ainda, um percurso de nulificação do acontecimento, o que representa, também, a intensificação do próprio mito. "Ninguém nem mais se lembrava dela", na primeira frase do texto, é retomada a variante, "ficaria sem choros e sem lembranças". No entanto, a própria natureza é pródiga para acolher e a "cova" é o refrigério que prepara a redenção. O ápice da história está no último termo "capim-azul", que no plano da significação simbólica associa-se à transitoriedade do mundo e da vida. "Capim-azul”, pois, é um termo que dá início a um novo mito, de onde posso inferir um espaço mágico, onde os valores humanos deixam de ter importância. A transmutação 
da cor sublinha a configuração do sagrado, no plano simbólico e, no plano da história, pode ser verbalizado como uma metáfora do perdão:

[...] as esporas apareceram em todas as refeições, como um vaso, uma compoteira, uma terrina. Na grande cama de casal [...] pelas noites sem fim, ela não conseguia tirar os olhos do nicho, na luzinha da lamparina. Não adiantava querer dormir, as esporas estavam dentro da cabeça, claras, e o som também era uma miragem. A descida durou um ano [...] até que um dia veio a morte, num fim de tarde, num meio de verão, com cigarras e cheiro de mel, só: morreu sentada, o vigia olhando ela e ela olhando para as esporas. Em cima dela, na cova, onde ficaria sem choro e sem lembranças, altura dos peitos, somente capim azul (GEP, p.58).

\section{À guisa de complemento}

Pensar o mito como uma representação da realidade é acatar também uma perspectiva modificante, o homem instalado no seu espaço, em busca de soluções para a equação realidade/verdade, reconhecendo-se que há muitos mundos e muitas realidades igualmente verdadeiras. Sob este aspecto, situa-se o mundo da cultura popular, receptáculo da memória coletiva, envoltório de uma cosmovisão em que prevalecem os valores cultivados pelo povo, num espaço do povo, num tempo também marcado pela presença do povo. Consciente da necessidade de restaurar a cultura do povo é que Borba Filho tornouse um escritor diferente, na tentativa de apreender o mundo popular tal como ele se apresenta, nos misteres populares.

Sabendo que "a arte não só representa como transfigura o que representa, concedendo-lhe um significado espiritual ou tornando este sentido manifesto na substância" (CRIPPA, 1975, p.64), acrescento que no texto "O almirante" (GEP, p.1-13), já estudado sob outro 
enfoque, como em outros textos deste escritor, tudo se transfigura, importando menos o significado explícito que a elaboração do senso estético que encaminha para o sentido latente, veiculado pelo tema ou pelo discurso. E a cultura de resistência, que em Borba Filho está no ápice de sua presença no mundo da literatura, manifesta-se duplamente: ou como retenção dos valores da cultura popular ou, ainda, como um recurso para desenvolver uma literatura comprometida com a realidade, naquilo que se apresenta como espelho de uma estrutura injusta, como se encontra também em outros literatos nordestinos, em que enfoco Ferreira Gullar, Jorge Amado, Graciliano Ramos e tantos outros que põem a sua arte a serviço do povo que representam. Da produção de histórias curtas de Borba Filho, digo com Stort (1993, p.48) que: "como o real é produzido segundo as vivências pessoais e culturais, o real é fantástico, e o fantástico é real”. Sob este aspecto, o texto acima referido é um bom exemplo, principalmente se for acatada a perspectiva da imaginação, nas suas variadas funções, como está em Stort (1993):

a) função objetivadora e libertadora que supre ausências afetivas e desvela anseios: "Ele gostava da névoa e tentava agarrar os fiapos brancos [..] não conseguia fugir ao encantamento" (p.1);

b) função comunicativa, de autoconhecimento e de conhecimento do mundo, comunicação consigo mesmo e com o outro: "Siri não perde muito tempo, conhece sua força, ataca hoje à noute?" (p.4);

c) função crítica e melhor percepção da realidade: "Era dono de uma grande fábrica, de um grande latifúndio, de bichos e gente" (p.5);

d) função de apoio ao desenvolvimento racional e enriquecimento da experiência: "[...] à noite recebendo os amigos e correligionários políticos, horas a fio discutindo preços de utilidades, 
medidas eleitoreiras, problemas com operários, situação do município" (p.5);

e) função motivadora, desenvolvimento de sentimentos constitutivos da vida: "[...] olha para a esquerda e vê a mulher, contemplando-o é uma mulata de cabelos lisos e lustrosos, quer ser dele, vê-se" (p.4);

f) função criadora, reveladora de problemas e busca de resposta: "Uma coisa que andava aqui dentro da cuca sem eu saber o que era e que de repente fiquei sabendo" (p.6).

Estas funções da imaginação, que servem de lastro para a análise do texto hermiliano, respaldam o mito e servem de alavanca para a criatividade do autor. Indo além das palavras, Borba Filho, através de um contexto mítico que governa o texto que está na superfície, desenvolve tendências que podem ser de sublimação ou de rebaixamento, situação em que a ideologia gera a comunicação artística. No conto "O almirante", as imagens do fandango se destacam pela exploração sonora da linguagem, quando "todas as formações verbais aparecem como entidades míticas, providas de determinados poderes míticos" (CRIPPA, 1975, p.64), que radicam o acontecer:

Olé, olé, olé ô triques, ô Maria, olé, Joaquim José Fidélis está preso no limoeiro, olé, olé, olé ô triques, ô Maria, olé. Senhor Mestre Calafati, calafete este navio, do mar lá fora não são como cá no rio olé, olé olé, ô triques, ô Maria, olé. O pombo vai voando, no bico levou uma flor, olé, olé, olé, ô triques, ô Maria, olé. Avoando foi dizer viva ao nosso imperador, olé, olé, olé, ô triques, ô Maria, olé (GEP, p.3).

Evidenciando o elemento mítico, o próprio nome da personagem é uma imagem mitificada, "Almirante Siri”, nome ampliado, quando a 
mesma personagem se identifica como ator, o mito, pois, inserido na representação: "porque eu sou o Almirante Siri do Fandango Verdes Mares Bravios da Minha Terra da Freguesia de Nossa Senhora da Conceição dos Palmares" (GEP, p.13).

Neste texto, o discurso oral se patenteia no tecido da narrativa, enquanto fala das personagens e enquanto discurso do narrador:

A chegada do navio-escola coincidiu com uma ideia brilhante que espocou no quengo do Almirante Siri [...] Olha, Pitinho, acho que a coisa vai funcionar. Que coisa? Uma coisa que andava aqui dentro da cuca sem eu saber o que era e que de repente fiquei sabendo (GEP, p.5-6).

De profissão primitiva, pescador de caranguejo, o Almirante Siri veicula um outro nível de cultura, agora no plano material. O narrador, fazendo uso da onomatopeia, explora a sonoridade da linguagem, quando destaca os elementos da cultura, como meio de subsistência: "Tratava apressadamente de fazer as rodilhas de caranguejo, nessas vezes bem chocas, saía do mangue no chape-chape [...], punha-se a andar, em quinze minutos vencia a distância que o separava do mercado, postava-se atrás do balcão dos caranguejos [...]" (GEP, p.1).

Num outro plano, os elementos da cultura popular trazem, à tona, o modo de vida do povo: "brincava e contava piadas; almoçava com uma pinga; encontrava um parceiro para jogar firo; deixava-se arriar na rede do seu mucambo" (GEP, p.2).

O tempo cíclico, aliado ao espaço, mantém a rotina, com a permanência do segundo e sequência do primeiro: "O dia se repetia. Somente aos sábados (o domingo não contava: era todo ele uma diversão só) saía dessa rotina para se dedicar, com toda seriedade, à grande paixão de sua vida" (GEP, p.9), situação em que o mito perde a sua instabilidade para instaurar um novo mito, qual seja, o de nivelamento entre classe subalterna e classe dominante. 
A imaginação de Borba Filho se desenvolve em várias funções, instaurando-se o domínio dos "possíveis" na manutenção do mito, como:

a) recorrência à memória para localizar o passado no presente: "e ficou rememorando a sua impressão de vinte anos atrás, quando o encontrou pela primeira vez à frente da turma da pesada, já figura lendária" (GEP, p. 46);

b) o arranjo da magia da linguagem: "[...] esgarçando nuvens com os dedos e passando os fiapos em suas barbas para mais embranquecê-las [...] deixara de agarrar fiapos de nuvens da madrugada, já que sua barba estava toda prateada" (GEP, p.46-47);

c) a presença do maravilhoso: "[...] sentara no paredão e bebia pelo gargalo de uma garrafa que lhe fora levada por um sacristão morto havia mais de cem anos [...], o amigo voou, estava no paredão, ao lado de Da Peixa, as pernas balançando no vazio" (GEP, p.47);

d) a teatralização dos espetáculos populares, como o Bumba-meu-boi, que Borba Filho diz ser a síntese de todas as representações populares da cultura (BORBA FILHO, 1966).

Há temáticas que envolvem o realismo mágico, o espaço onde se desenvolvem os eventos transforma-se num espaço mágico. E a perspectiva mítica que foi trabalhada é pertinente à aplicação de uma abordagem que capte os dados contidos na arte, na sociedade, na linguagem, na cultura e outros. Seria exagero dizer que, literariamente, tudo se adequa ao mito? E Borba Filho, qual outro "Proteu, a divindade que podia assumir qualquer forma" (LEMINSKI, 1994, p.67), apreende variadas formas do mundo real por ele transfigurado, sem perder de vista o caminho por ele traçado para atingir o seu objetivo, que como todo mito possibilita reatualizar o existente, enquanto se manifesta como linguagem que recria o real, amparado pelo plano do imaginário 
que representa um mundo ambivalente e ambíguo, visto como um hipertexto da realidade, atuando como transformador de sentidos.

E se os próprios deuses se transformam, o mito da transformação do mundo dos homens se justifica por esta analogia dos tempos primordiais. E, assim, encerro este capítulo, captando o pensamento de Debray (1993, p.21): "quem recua no tempo avança no conhecimento". Borba Filho recua no tempo para captar as raízes de uma cultura que evidencia a memória coletiva e tonifica a tradição, sendo ele mesmo, enquanto engajado nas lides da literatura, um representante da coletividade que, disseminando a cultura, cresceu no plano do real pelo conhecimento do Homem, da Vida e pelo seu instrumento de trabalho, a Linguagem, contribuindo para difundir a Literatura Brasileira do Nordeste que se destaca pela firmeza do seu imaginário, caracterizando, como explica Barthes (1984), noutras situações, o mundo humano dos conflitos, dos desejos e das resistências. 